\title{
Process parameters influence on mechanical strength of direct bonded surfaces for both materials: silica and Zerodur ${ }^{\circledR}$ glasses
}

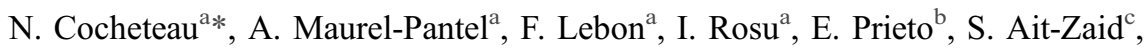 \\ I. Savin De Larclause ${ }^{\mathrm{c}}$ and Y. Salaun ${ }^{\mathrm{d}}$ \\ ${ }^{a}$ LMA, Mechanics and Acoustics Laboratory, CNRS, UPR 7051, Aix-Marseille University, \\ Centrale Marseille, 31, Chemin Joseph Aiguier, F-13402, Marseille Cedex 20, France, ${ }^{b}$ LAM, \\ Marseille Astrophysics Laboratory, CNRS-INSU, UMR 7326, Aix-Marseille University, \\ Technopôle Château-Gombert 38, rue Frédéric Joliot-Curie 13388, Marseille Cedex 13, France; \\ ${ }^{c}$ CNES, National Center for Spatial Studies, 18 Avenue Édouard Belin 31400 Toulouse, France; \\ ${ }^{d}$ Winlight Optics, 135 rue Benjamin Franklin, ZA Saint Martin, 84120 Pertuis, France
}

\begin{abstract}
Direct bonding is of particular interest for optical system manufacturing for spatial application. This technology is already used in terrestrial optical system manufactur-ing because of the very high precision of the process and complex geometries are able to bond. However, even if a first prototype already passed with success space environment test, quantification and improvement of the mechanical strength of assemblies are essential to validate the assembly's life expectancy and to validate the European Space Agency standards. So, this work proposes to study the influence of process parameters, such as roughness, relative air humidity during room temper-ature bonding, annealing time and temperature, on mechanical strength of an elementary mechanical structure using a double shear test procedure and cleavage tests. At the same time, the performances of fused silica and Zerodur ${ }^{\mathbb{B}}$ glasses are compared. For the process considered in this study, a parallel is made between chemical phenomena, surface roughness and mechanical strength. In the end, cleavage tests confirm the choice of the optimal process parameters and highlight a damaging phenomenon of bonded interfaces with successive re-adhesion.
\end{abstract}

Keywords: direct bonding; mechanical strength; bonding energy; double shear test; annealing temperature; roughness; humidity; annealing time; silica glasses; Zerodur ${ }^{\mathbb{B}}$ glasses

\section{Introduction}

Direct bonding consists in joining two surfaces without the use of any adhesives or additional material.[1,2] Usually, by bringing two flat, well-polished surfaces into contact at room temperature, they locally attracted to each other by Van der Waals or hydrogen bonds, and adhere or bond. Direct bonding is also known as wafer bonding or molecular bonding. Direct bonding is a process involved in micro-fabrication process on micro-electronics. The main applications are on silicon-on-insulator devices. Siliconbased sensor and actuators, electronics substrates are other examples of wafer bonding applications.[3-5] More recently, this process is used in the manufacturing of highperformance optical systems for terrestrial application such as Fabry-Perot

*Corresponding author. Email: cocheteau@1ma.cnrs-mrs.fr 
interferometers, prism assemblies, etc. For instance, this bonding process has been used in the manufacture of the largest slicer ever used in the multi unit spectroscopic explorer (MUSE) for the very large telescope (VLT) [6] as related in Figure 1. Nowadays, they are of particular interest for spatial instruments applications. Indeed, this is a high-precision production process and assemblies obtained present a dimensional stability due to the fact that no mechanical part or glue is required. In addition, since no adhesive materials are used in those processes, the risks of contamination associated with degassing are avoided, which is another advantage in spatial context. A first prototype has already passed with success the mechanical and thermal environment of space [7] where the constraints involved (thermal fatigue, accelerations, vibrations, etc.) are very different from those encountered on Earth. However, a better understanding of the assemblies' mechanical strength behaviour is required to validate the system life expectancy and to meet the European Space Agency standard.

Mechanical strength of those bonded interfaces depends on the interface defects and the nature of bonds involved. Indeed, room temperature bonding needs flatness and roughness perfectly controlled, and no particles contaminations on surfaces.[8-12] Moreover, room temperature bonding is usually relatively weak; consequently, for some applications, the bonded assemblies undergo an annealing treatment causing changes in the nature of bonds responsible for adhesion and thus strengthen the bond across the interface. $[13,14]$ Therefore, it is necessary to quantify the bonding strength and to improve the mechanical performance of adhesive bonds using the confidential Winlight Optics Company process of surface preparation and without degrading optical performances of the material used or damaging coating applied on bonded optical system. In this study, the Winlight Optics Company process is considered. Thus, it is proposed to improve the understanding of multi-physical couplings and multi-scale mechanical phenomena of direct bonding, by quantifying links and close interactions between chemical phenomena, process parameters (annealing temperature and time, humidity level, etc.), surface roughness and mechanical strength. The final aim consists to understand mechanisms at the interface of mechanical strength reinforcement and to find a way to improve treatment of the assemblies in order to obtain a better structural behaviour. So, in this work, the influence of some process parameters, such as roughness, relative air humidity during room temperature bonding, annealing time and temperature, on mechanical strength of an elementary mechanical structure is

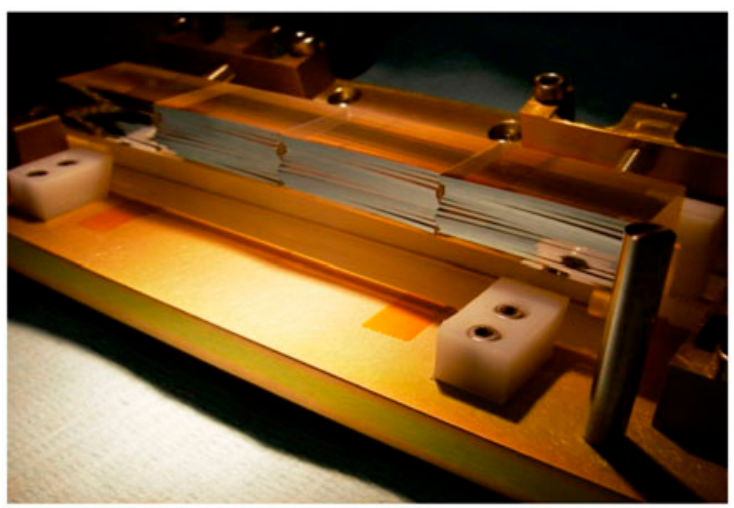

Figure 1. Slicer developed in the MUSE for the VLT.[6] 
investigated. First, fused silica glasses and Zerodur ${ }^{\circledR}$ glasses, which are specific materials used for spatial optical applications, are quickly presented as well as the sample preparation. At the beginning, the nature of both the materials surfaces is compared using wetting tests and X-ray spectroscopy analysis (XPS). Then, the mechanical strength of bonded interfaces of each kind of samples is also compared using double shear experiments. And performances of fused silica and Zerodur ${ }^{\circledR}$ glasses are compared. Afterwards, according to the results, the choice of the optimal process parameters is made in order to increase mechanical strength without degrading material properties. Lastly, a comparison between samples with initial parameters (bonding at ambient temperature) and optimal parameters is performed using cleavage tests.

\section{Background on direct bonding process}

\subsection{Surface preparation}

Direct bonding is possible as long as the two surfaces have similar geometries and require clean surfaces free of contaminants.[10,15] Therefore, first steps of the Winlight Optics Company process consist in physical and chemical preparation of surfaces. Several polishing of both surfaces to adhere were manually performed in order to obtain the exact surface roughness (here, roughness is always less than $1 \mathrm{~nm}$ RMS), flatness and deflection required. Indeed, a high level of roughness results in a weak contact zone and thus in the occurrence of defects during the bonding process. When the roughness is too great, bonding becomes impossible.[16-19] Then, surfaces undergo a chemical treatment in order to eliminate any contaminating particles.[20] With ambient water, free silicon surfaces are recovered by silanol $(\mathrm{Si}-\mathrm{OH})$ groups which are the precursor of the bonding [21,22]:

$$
\mathrm{Si}-\mathrm{O}+\mathrm{H}_{2} \mathrm{O} \rightarrow \mathrm{Si}-\mathrm{OH}
$$

Then, silanol groups react with ambient humid air to form clusters of water $[13,14]$ on surfaces as shown in Figure 3(a). Indeed, formation of clusters is energetically favourable compared to the formation of one silanol bond. The adsorption of water can be written as:

$$
-\mathrm{OH}_{\mathrm{I}}+\mathrm{H}_{2} \mathrm{O} \rightleftarrows-\mathrm{OH}_{\mathrm{II}}+\mathrm{H}_{2} \mathrm{O}_{\mathrm{I}}, \quad \Delta_{\mathrm{R}} \mathrm{H}=6 \mathrm{kcal} \mathrm{mol}^{-1}
$$

And the adsorption of an additional molecule of water can be written as:

$$
\mathrm{H}_{2} \mathrm{O}_{\mathrm{I}}+\mathrm{H}_{2} \mathrm{O} \rightleftarrows \mathrm{H}_{2} \mathrm{O}_{\mathrm{I}}+\mathrm{H}_{2} \mathrm{O}_{\text {II }}, \quad \Delta_{\mathrm{R}} \mathrm{H}=10,5 \mathrm{kcal} \mathrm{mol}^{-1}
$$

Thus, the water form clusters on the surface before all the $\mathrm{Si}-\mathrm{OH}$ groups have adsorbed water molecules. With this chemical treatment, we seek to have the more silanol groups possible on both surfaces. On Figure 2, one component of the roughness is represented, each line represents a bonding site, and obviously a lack of bonding sites causes incomplete bonding.

\subsection{Room temperature bonding}

Once physical preparation and surface treatment have been completed, surfaces are brought into contact and bonding occurs between clusters of the two surfaces. A process of capillarity occurs due to the humid air trapped between the surfaces.[8] By 


\section{Wafer surfaces :}

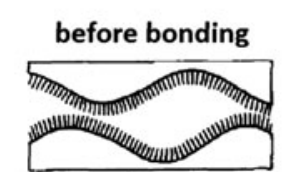

Fully hydrated surfaces

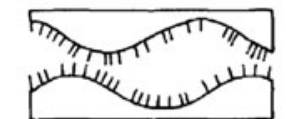

Poor local hydrophilization of surfaces
After spontaneous RT bonding
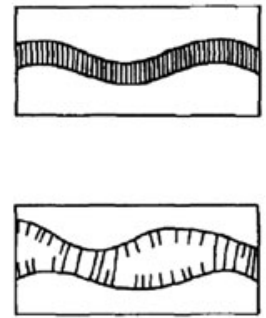

After RT bonding by means of static pressure
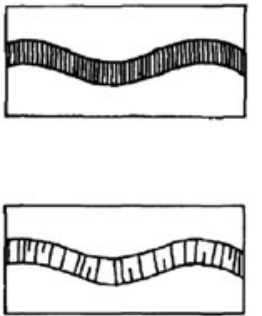

Figure 2. Behaviour of surfaces during room temperature bonding according to their hydroxylated rate (from [13]).

applying a slight local pressure, the surfaces are brought closer together, and hydrogen bonds developed between molecules of water present at the interface and the two surfaces. A bonding wave propagates from the contact point through the whole sample, resulting in the bonding of the surfaces. Molecules of water migrate from the bonding interface and/or diffuse at the interface, bringing the surfaces even closer together and initiating silanol-silanol covalent bonds.[14,23,24]

\subsection{Evolution of bonded interfaces with temperature}

In order to obtain a stronger or irreversible sealing by increasing the number of covalent bonds, it is necessary to change the nature of bonds at the interface by applying for instance a thermal treatment (Figure 3). Indeed, between 25 and $200{ }^{\circ} \mathrm{C}$, surfaces are contacted via clusters of waters.[13,14] When temperature is lower than $110^{\circ} \mathrm{C}$, chemical reactions at the bonded interface are the same than during room temperature bonding i.e. formation of hydrogen bonds between molecules of water and surfaces.

(a)

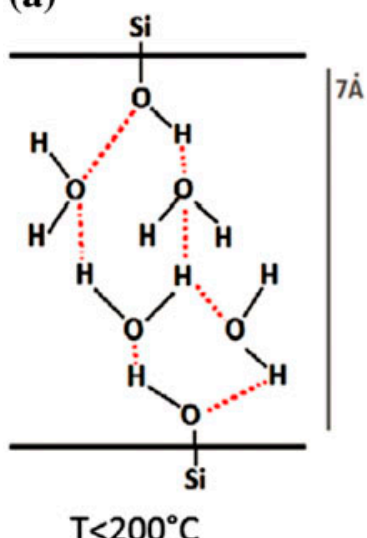

(b)

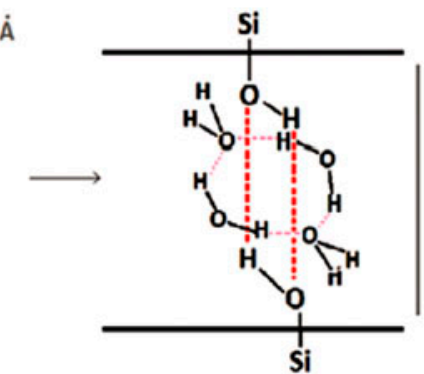

$200^{\circ} \mathrm{C}<\mathrm{T}<700^{\circ} \mathrm{C}$ (c)

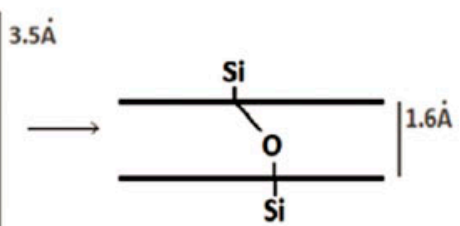

$\mathrm{T}>700^{\circ} \mathrm{C}$

Figure 3. Evolution of the nature of bonds at the interface during thermal treatment. 
(1) Between 110 and $150{ }^{\circ} \mathrm{C}$, molecules of water start to release (Phase I).

(2) When temperature is between 200 and $700{ }^{\circ} \mathrm{C}$, there is formation of cyclic tetramers of water; surfaces are directly contacted via double hydrogen bond (Phase II) as shown in Figure 3(b).[25]

(3) $\mathrm{Up}$ to $700^{\circ} \mathrm{C}$, the polymerization reaction is triggered, resulting in the formation of covalent siloxane bonds (Phase III, Figure 3(c)) [13,14]:

$$
\mathrm{Si}-\mathrm{OH}+\mathrm{HO}-\mathrm{Si} \leftrightarrows \mathrm{Si}-\mathrm{O}-\mathrm{Si}+\mathrm{H}_{2}
$$

\section{Materials and test methods}

\subsection{Materials}

In optical applications, three materials are mainly used: fused silica glasses, Zerodur ${ }^{\circledR}$ and Zinc Selenide (ZnSe). In this work, we chose to study two of them, the fused silica glasses and Zerodur ${ }^{\circledR}$ glasses, which are the most commonly used in spatial optical applications with a reasonable cost.

Silica is the main constituent of glass. Crystalline silica has a tetrahedral structure wherein each tetrahedral unit $\left(\mathrm{SiO}_{4}\right)$ contains a silicon atom at the centre and four oxygen atoms occupy the vertices of the tetrahedron. However, glass is an amorphous material, therefore, it shows major structural disorder. Fused silica glass can be seen as an anarchistic stacking of $\mathrm{SiO}_{2}$ tetrahedra in which only short range order is maintained.

Zerodur $^{\circledR}$ is a glass-ceramic type invented in 1968 by optical materials producer Schott $A_{G^{\mathrm{TM}}}$ and it is specifically designed for astronomy observations in terrestrial and spatial fields. The special feature of this material comes from its thermal expansion coefficient which is almost nil and homogeneous in all directions. So, Zerodur ${ }^{\mathbb{B}}$ offers a very high thermal stability.[26] It is a non-porous glass ceramic composed of $78 \%$ of nanocrystals with a quartz structure trapped in residual vitreous phase. Crystals have a negative thermal expansion coefficient and the glass has a positive thermal expansion coefficient which offset, giving to Zerodur ${ }^{\circledR}$, its weak thermal expansion coefficient. Zerodur $^{\circledR}$ is composed of $57.2 \%$ of silica $\left(\mathrm{SiO}_{2}\right), 25.3 \%$ of aluminium oxyde $\left(\mathrm{Al}_{2} \mathrm{O}_{3}\right)$, $6.5 \%$ of phosphorous pentoxide $\left(\mathrm{P}_{2} \mathrm{O}_{5}\right), 3.4 \%$ of lithium oxide $\left(\mathrm{LiO}_{2}\right), 2.5 \%$ of titanium dioxide $\left(\mathrm{TiO}_{2}\right), 1.8 \%$ of zyrconium dioxide $\left(\mathrm{ZrO}_{2}\right), 1 \%$ of magnesium oxide $(\mathrm{MgO})$, $0.5 \%$ of arsenic trioxide $\left(\mathrm{As}_{2} \mathrm{O}_{3}\right)$ and $0.2 \%$ of sodium oxide $(\mathrm{NaO})$. Small changes can occur in coefficient of thermal expansion (CTE) with the annealing treatment and can affect the geometric accuracy and stability of the high-precision optical assemblies. So, it is interesting to note that for Zerodur ${ }^{\circledR}$, there are three temperature ranges where different behaviours of CTE are observed [26]:

(1) When $T>700^{\circ} \mathrm{C}$ (ceramising range).

(2) Between $320^{\circ} \mathrm{C}<T<700{ }^{\circ} \mathrm{C}$ steady state.

(3) Between $130{ }^{\circ} \mathrm{C}<T<320^{\circ} \mathrm{C}$ (superior relaxation range).

(4) Between $40{ }^{\circ} \mathrm{C}<T<130^{\circ} \mathrm{C}$ steady state.

(5) Between $-70{ }^{\circ} \mathrm{C}<T<40{ }^{\circ} \mathrm{C}$ (inferior relaxation range).

For temperature above $700{ }^{\circ} \mathrm{C}$, the material ceramising continues in irreversible way, changes in material properties appear and the CTE is irreversibly changed. Figure 4 relates limits and temperature influence on dimensional stability for samples 


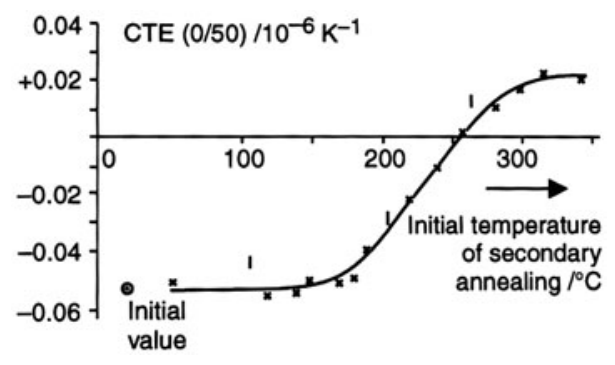

Figure 4. Variation of the $\mathrm{CTE}\left(0^{\circ} \mathrm{C} ; 50^{\circ} \mathrm{C}\right)$ - first cooling at $0.1 \mathrm{~K} / \mathrm{min}-$ as a function of the initial temperature of a secondary cooling in open air to room temperature.[26]

initially annealed at different temperatures and cooled at room temperature. Up to annealing temperature about $130{ }^{\circ} \mathrm{C}$, there is no modification in CTE. Above this temperature, CTE increases to a specific constant value, in order to not degrade the thermal expansion parameter (CTE), the cooling speed has to be choosen between 1 and $6{ }^{\circ} \mathrm{C} / \mathrm{h}$ (cooling procedure during Zerodur ${ }^{\circledR}$ manufacturing).[26]

\subsection{Wetting tests and $X$-ray spectroscopy}

To characterize samples surfaces, wetting tests and XPS were performed on fused silica glass and Zerodur ${ }^{\circledR}$ surfaces of two kinds: never bonded surfaces and bonded then debonded surfaces (called, respectively, in the following: non-bonded and debonded surfaces). In order to determine the surface energy of the both surfaces to adhere, wetting tests are performed. The angle of contact was determined by approximating the drop profile using the software Drop Shape Analysis V.1.80. Results summarized in Table 1 shown that surface energy is greater for Zerodur ${ }^{\circledR}$ samples. So, this material seems to be a better candidate for direct bonding. Indeed, the bonding will obviously be easier to perform when the surface energy of adhesion is high and furthermore when roughness is low.[9,12] The difference in surface energy between non-bonded and debonded surfaces was found to be approximately 20\%. The results of the XPS tests presented in Figure 5 show that the spectra of debonded and non-bonded surfaces were identical a priori. The slight differences between fused silica and Zerodur ${ }^{\circledR}$ are attributable to the differences in the chemical composition of the two materials: the silicon atoms do not have the same environment in both cases. Surface wettability and XPS results confirm the reversibility - with damaging - of the process.[27] Indeed, one characteristic of the direct bonding process when no thermal treatments are applied is the reversibility of the bonding.[28]

Table 1. Surface energy for fused silica glasses and Zerodur ${ }^{\circledR}$ glasses.

\begin{tabular}{|c|c|c|c|}
\hline Material & $\begin{array}{c}\gamma_{s}\left(\mathrm{~mJ} / \mathrm{m}^{2}\right) \\
\text { surface energy }\end{array}$ & $\begin{array}{c}\gamma_{s}^{d}\left(\mathrm{~mJ} / \mathrm{m}^{2}\right) \\
\text { dispersive } \\
\text { component of } \\
\text { surface energy }\end{array}$ & $\begin{array}{l}\gamma_{s}^{d}\left(\mathrm{~mJ} / \mathrm{m}^{2}\right) \\
\text { polar component } \\
\text { of surface energy }\end{array}$ \\
\hline Zerodur ${ }^{\circledR}$ & 51.59 & 27.69 & 23.91 \\
\hline Fused silica glasses & 48.57 & 29.49 & 19.19 \\
\hline Debond Zerodur ${ }^{\circledR}$ & 40.43 & 23.96 & 16.48 \\
\hline Debond fused silica glasses & 41.52 & 26.11 & 15.41 \\
\hline
\end{tabular}



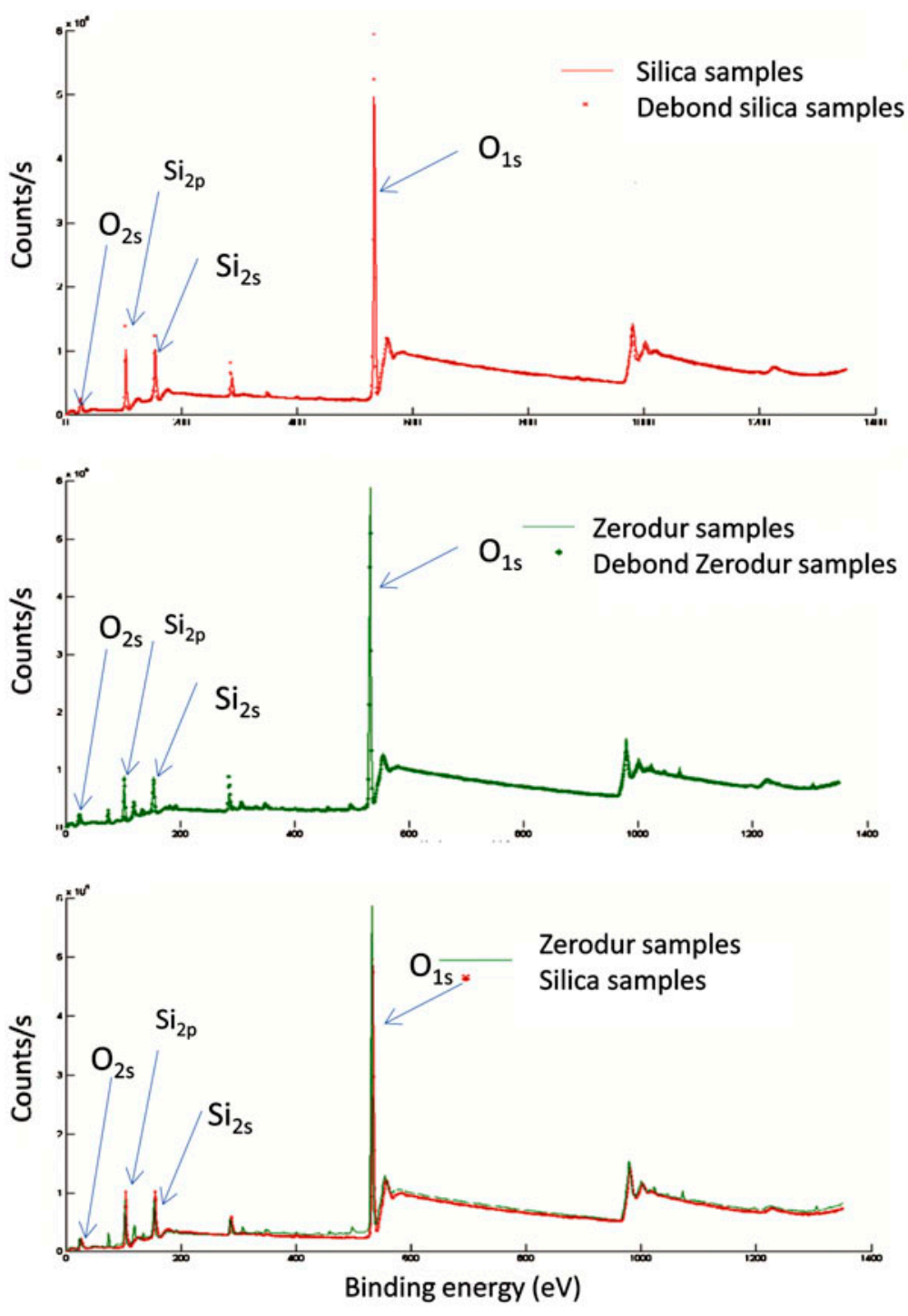

Figure 5. XPS spectra for silicon glasses and Zerodur $^{\circledR}$ glasses.

\subsection{Mechanical experiments}

The objective of this part is to find the best candidate for direct bonding process between fused silica glasses and Zerodur ${ }^{\circledR}$ and to find the optimal parameters of the Winlight Optics Company process to increase mechanical strength of bonded assemblies. Therefore, we study the influence of some process parameters - roughness, relative air humidity during room temperature bonding, annealing time and temperature - on the mechanical strength of an elementary mechanical structure using a double shear test procedure and a cleavage test by comparing the both materials. Double shear test specimen was chosen for two main reasons: cylinder assemblies are classically used in some Winlight Optics Company interferometer, and it is easier to manufacture a large 
number of small cylinders $(150 \times 3$ cylinders $)$ in glass with low roughness on each faces. The second test - the cleavage configuration - is the reference test for Winlight Optics Company and French National Centre for Spatial Studies (CNES). With these two mechanical tests, the influence of the surfaces treatment process on two failure modes (I \& II) is observed.

\subsubsection{Double shear tests}

The first mechanical test has been set up on a large number (150) of samples in double shear configuration based on cylinder shape. With this configuration, we obtain a pure shear stress state and misalignments are controlled with a good adjustment between steel experimental device and sample geometry. The tools were beforehand mounted on a tensile testing machine. Samples are constituted with two cylinders of $5 \mathrm{~mm}$ thickness and $10 \mathrm{~mm}$ diameter, and one cylinder of $5 \mathrm{~mm}$ thickness and $15 \mathrm{~mm}$ diameter bonded together as shown in Figure 6. Materials used are fused silica glasses and Zerodur ${ }^{\circledR}$ glasses. The sample is inserted into the upper part of the tool as shown in Figure 6, and then fixed to the lower part using a flange. The loading rate of the test is fixed at $1 \mathrm{~mm} / \mathrm{min}$. We measured the ultimate force necessary to release the interfaces and compared results under different conditions. We assume that, in this case, the ultimate force is proportional to the bonding energy due to the brittle behaviour of molecular bonding. Table 2 shows the 150 experiments made (five samples per test).

\subsubsection{Cleavage tests}

The second mechanical test has been set up on five samples in classic cleavage configuration to validate the choice of the optimal parameters. Samples are constituted with two blades of $10 \mathrm{~mm}$ of thickness, $40 \mathrm{~mm}$ of width and $40 \mathrm{~mm}$ of length direct bonded together. Each sample has been bonded with glue on aluminium experimental device mounted in a tensile testing machine as related in Figure 7. A vertical load is applied, in the same way the loading rate of the test is fixed at $1 \mathrm{~mm} \mathrm{~min}^{-1}$ and the ultimate

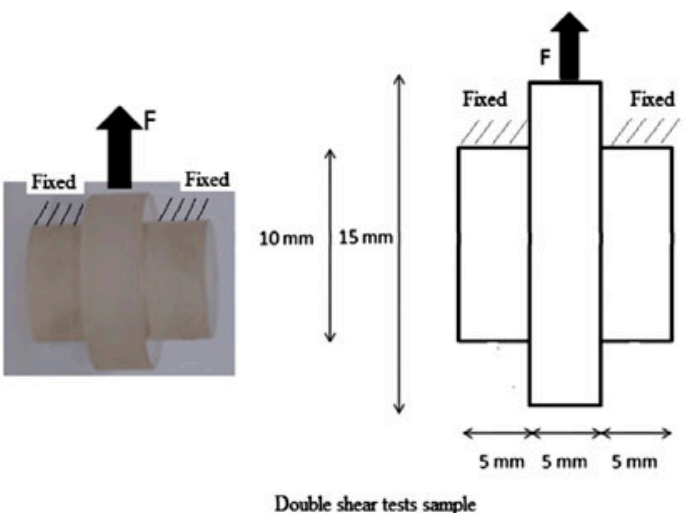

Figure 6. Sample and double shear experimental device.

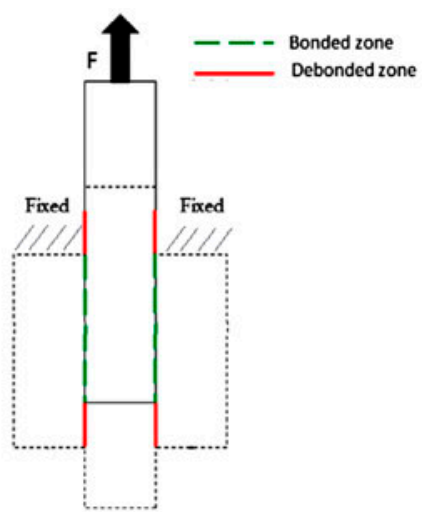

Double shear test sample during experiment 
Table 2. Summary of double shear tests performed (five samples per condition).

\begin{tabular}{|c|c|c|c|c|}
\hline Material & $\begin{array}{c}\text { Annealing } \\
\text { temperature }\left({ }^{\circ} \mathrm{C}\right)\end{array}$ & $\begin{array}{l}\text { Annealing } \\
\text { time (h) }\end{array}$ & $\begin{array}{l}\text { Roughness } \\
\text { (nm RMS) }\end{array}$ & $\begin{array}{l}\text { Humidity } \\
\text { level (\%) }\end{array}$ \\
\hline $\begin{array}{l}\text { Fused silica glass } \\
\text { (Reference) }\end{array}$ & 20 & $\infty$ & 0.4 & 55 \\
\hline Zerodur $^{\circledR}$ (Reference) & 20 & $\infty$ & 0.4 & 55 \\
\hline Fused silica glass & $\begin{array}{c}100,200,400,700,800, \\
900\end{array}$ & 15 & 0.4 & 55 \\
\hline Zerodur $^{(\mathbb{R}}$ & $100,150,200,400,550$ & 15 & 0.4 & 55 \\
\hline Fused silica glass & 200 & $\begin{array}{c}1,15,35 \\
120\end{array}$ & 0.4 & 55 \\
\hline Fused silica glass & 200 & 120 & $\begin{array}{c}0.2,0.4,0.6, \\
1\end{array}$ & 55 \\
\hline Zerodur ${ }^{\circledR}$ & 130 & 120 & $0.2,0.6,1$ & 55 \\
\hline Fused silica glass & $\mathrm{X}$ & $\mathrm{X}$ & 0.4 & $\begin{array}{l}32,55 \\
82\end{array}$ \\
\hline Zerodur $\left.^{(}\right)$ & $\mathrm{X}$ & $\mathrm{X}$ & 0.4 & $\begin{array}{c}32,55, \\
82\end{array}$ \\
\hline
\end{tabular}

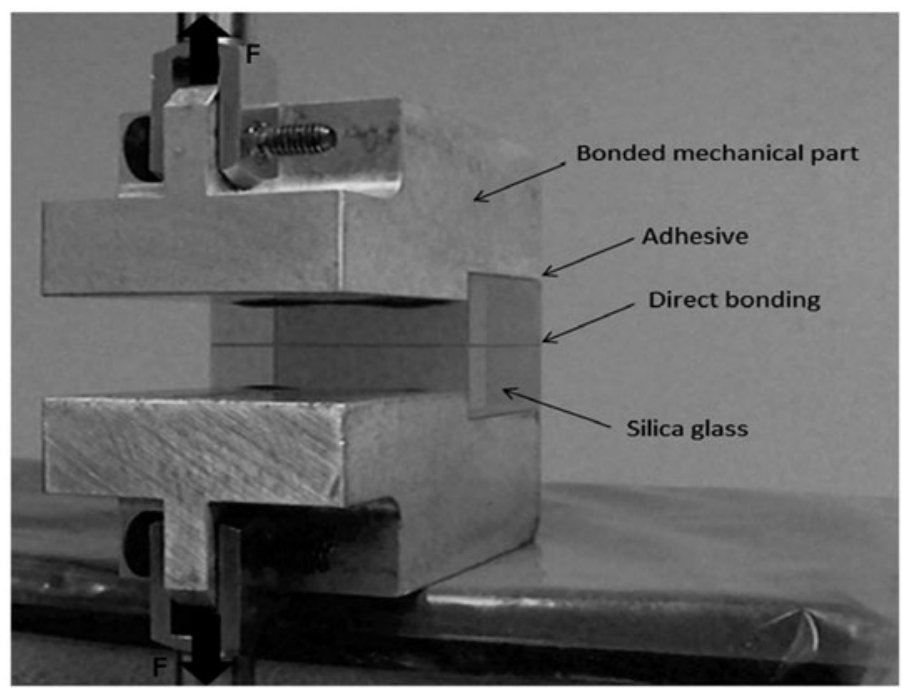

Figure 7. Sample and cleavage experimental device.

force is measured. With a finite element model considering an average stress value on a local zone, the maximal stress value is identified. Between each experiment on the same sample, surfaces are cleaned and re-adhered (without being polished anew).

\section{Results and discussion}

According to the adhesion mechanism presented in Section 2, parameters such as roughness, humidity level during room temperature bonding and annealing parameters are crucial for bonding. Indeed, bonding at room temperature is directly attached to the roughness of samples and to the presence of water cluster at the interface and therefore 
to the rate of air humidity during room temperature bonding. Moreover, samples undergo a thermal treatment; the nature of bonds responsible for adhesion, therefore, depends on the temperature range and the kinetics of the reactions triggered at the interface. Thus, in this section, we study the influence of the previous process parameters: the annealing temperature and time, the roughness combined with thermal treatment, and to finish the influence of the relative air humidity during the room temperature bonding as related in Table 2. With Zerodur ${ }^{\circledR}$ samples, we had chosen to work at temperatures below $550{ }^{\circ} \mathrm{C}$ in order to preserve the thermal expansion coefficient.

\subsection{Influence of annealing temperature}

Firstly, we have studied the influence of the annealing temperature. Results, presented in Figures 8 and 9, show that the mechanical resistance increases non-linearly with annealing temperature. This can be explained by the chemical mechanism of direct bonding. Indeed, when temperature is below $200{ }^{\circ} \mathrm{C}$, we have seen that silicon surfaces are contacted via water clusters. When temperature is lower than $110^{\circ} \mathrm{C}$, chemical reaction at the bonded interface are the same than during room temperature bonding (i.e. formation of hydrogen bonds between molecules of water and surfaces).
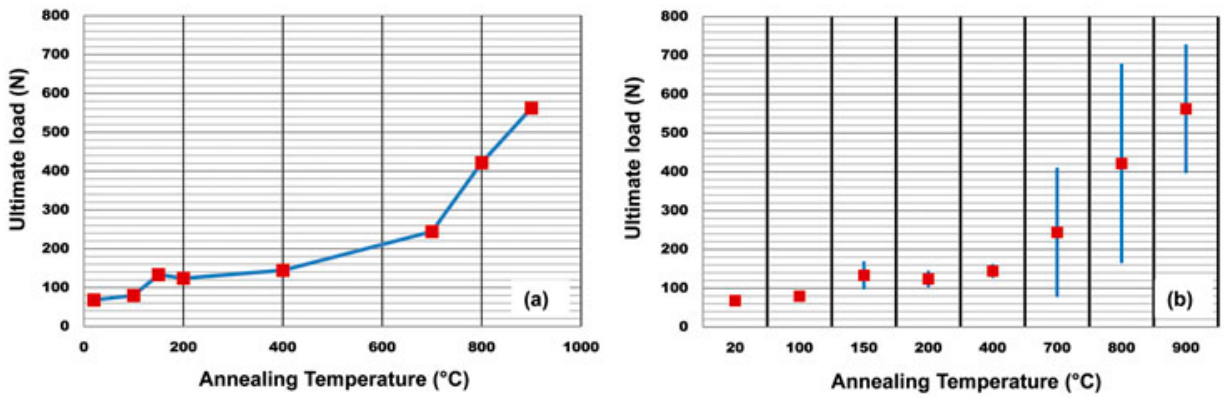

Figure 8. Annealing temperature influence on fused silica glass tested in double shear configuration: average values (a) and standard deviations (b) of measured ultimate loads.
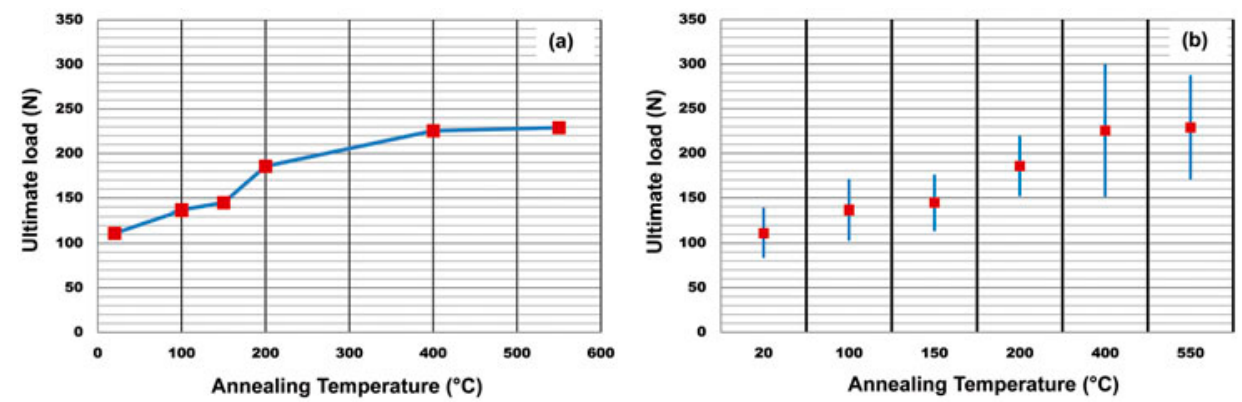

Figure 9. Annealing temperature influence on Zerodur ${ }^{\circledR}$ glass tested in double shear configuration: average values (a) and standard deviations (b) of measured ultimate loads. 
The bonding energy is governed by the number of silanol group bonded with water.[14,29] Between 110 and $150{ }^{\circ} \mathrm{C}$, the bonding energy increases due to the beginning of the releasing of molecular water. When temperature increases, there is formation of tetramers of water, surfaces are now directly contacted via double hydrogen bonds and the surfaces get closer. During this range of temperature, the bonding energy is limited by the area of contacted zone, the bonding energy slightly increases with the increasing of the contacted zone (Figure 10). Then, when temperature is up to $700{ }^{\circ} \mathrm{C}$, there is polymerization of covalent siloxane ( $\mathrm{Si}-\mathrm{O}-\mathrm{Si}$ ) bonds. $[13,14,30]$

For thermal treatment at $900{ }^{\circ} \mathrm{C}$, we do not observe a release along the interfaces but a fracture inside material of the bonded samples. It seems that the material is fused at the interface. Interface has the same behaviour that the pure crystal configuration and we can suppose that a single bloc of fused silica glass or Zerodur ${ }^{\circledR}$ is obtained as related on Figure 11. Moreover, the results confirm wetting tests results: the mechanical resistance is higher for Zerodur ${ }^{\circledR}$ samples.

\subsection{Influence of annealing time}

Then, we have studied the influence of annealing time. Figures 12-14 show an increase of the mechanical strength and the appearance of a plateau for the long annealing time (Figure 16). For low temperature, the bonding energy only depends on the number of hydrogen bonds. When temperature increases, the different reactions at the interface

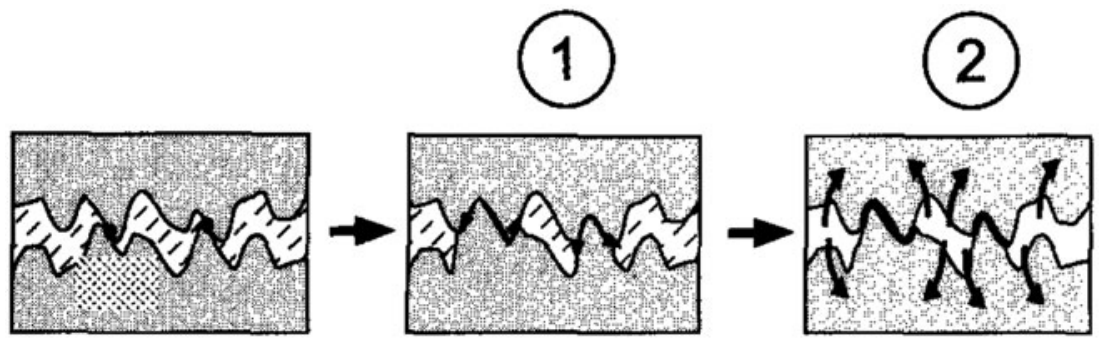

Figure 10. Evolution of the contacted zone (from [23]).
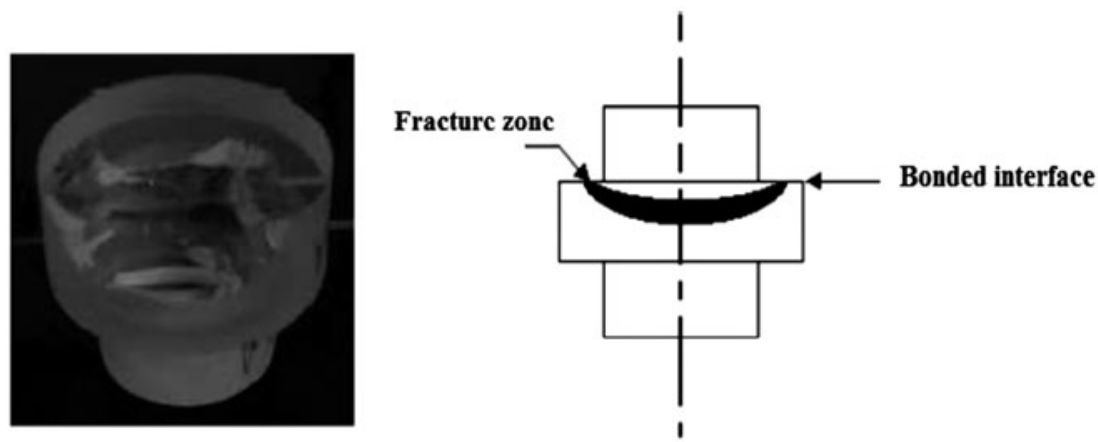

Figure 11. Fracture of fused silica glass sample annealed at $900^{\circ} \mathrm{C}$ during $120 \mathrm{~h}$. 

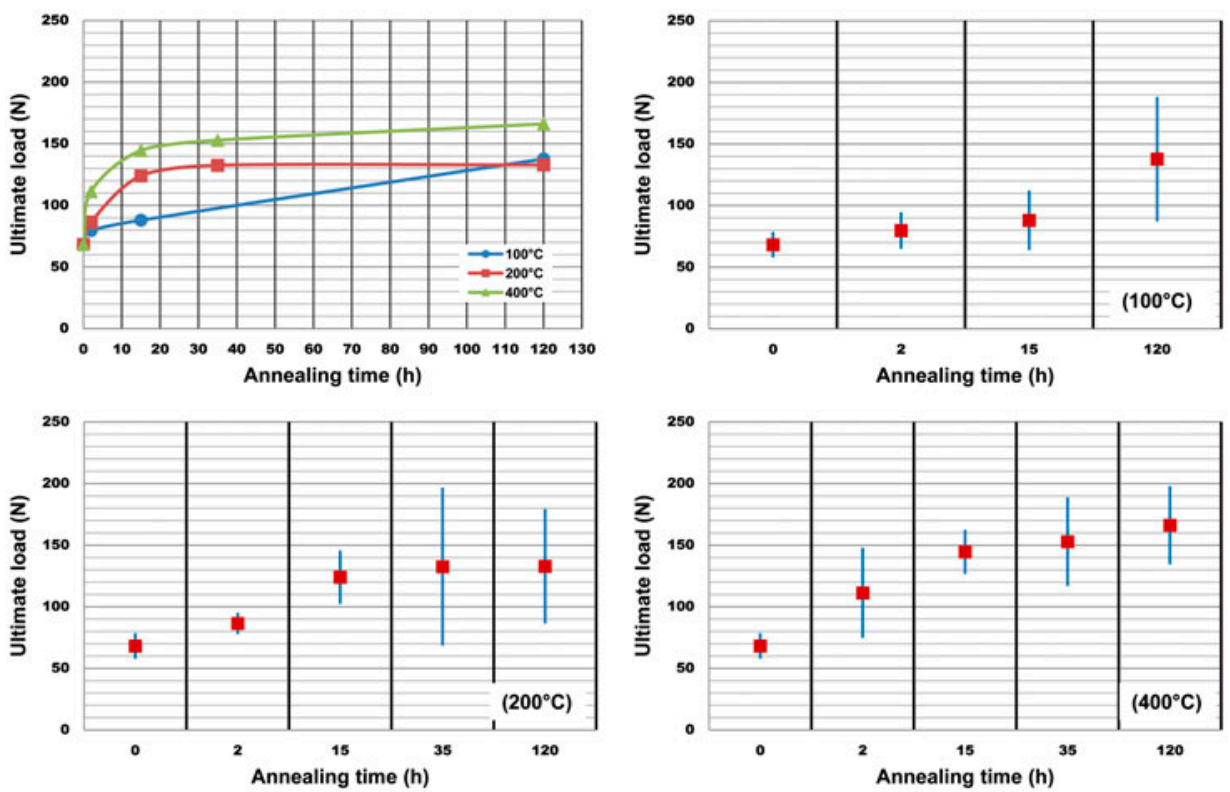

Figure 12. Annealing time influence at low temperatures on fused silica glass tested in double shear configuration: average values and standard deviations of measured ultimate loads.
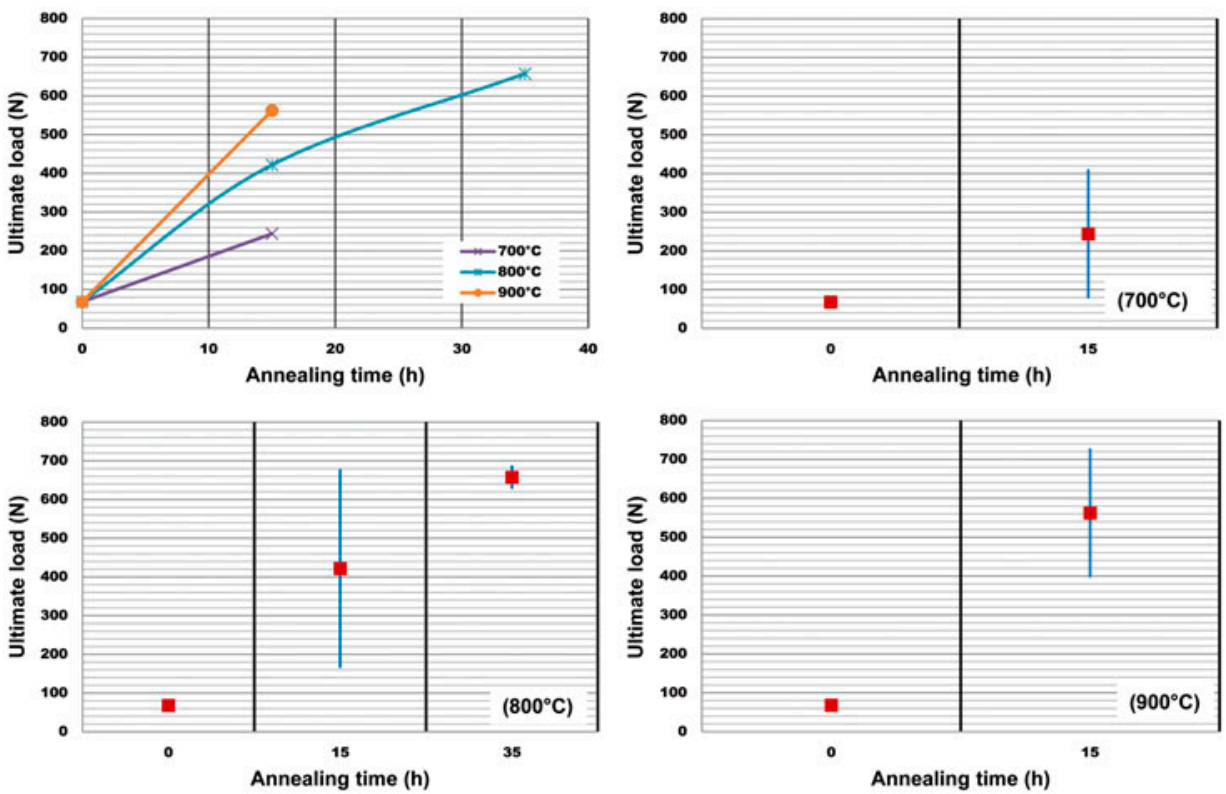

Figure 13. Annealing time influence at high temperatures on fused silica glass tested in double shear configuration: average values and standard deviations of measured ultimate loads. 

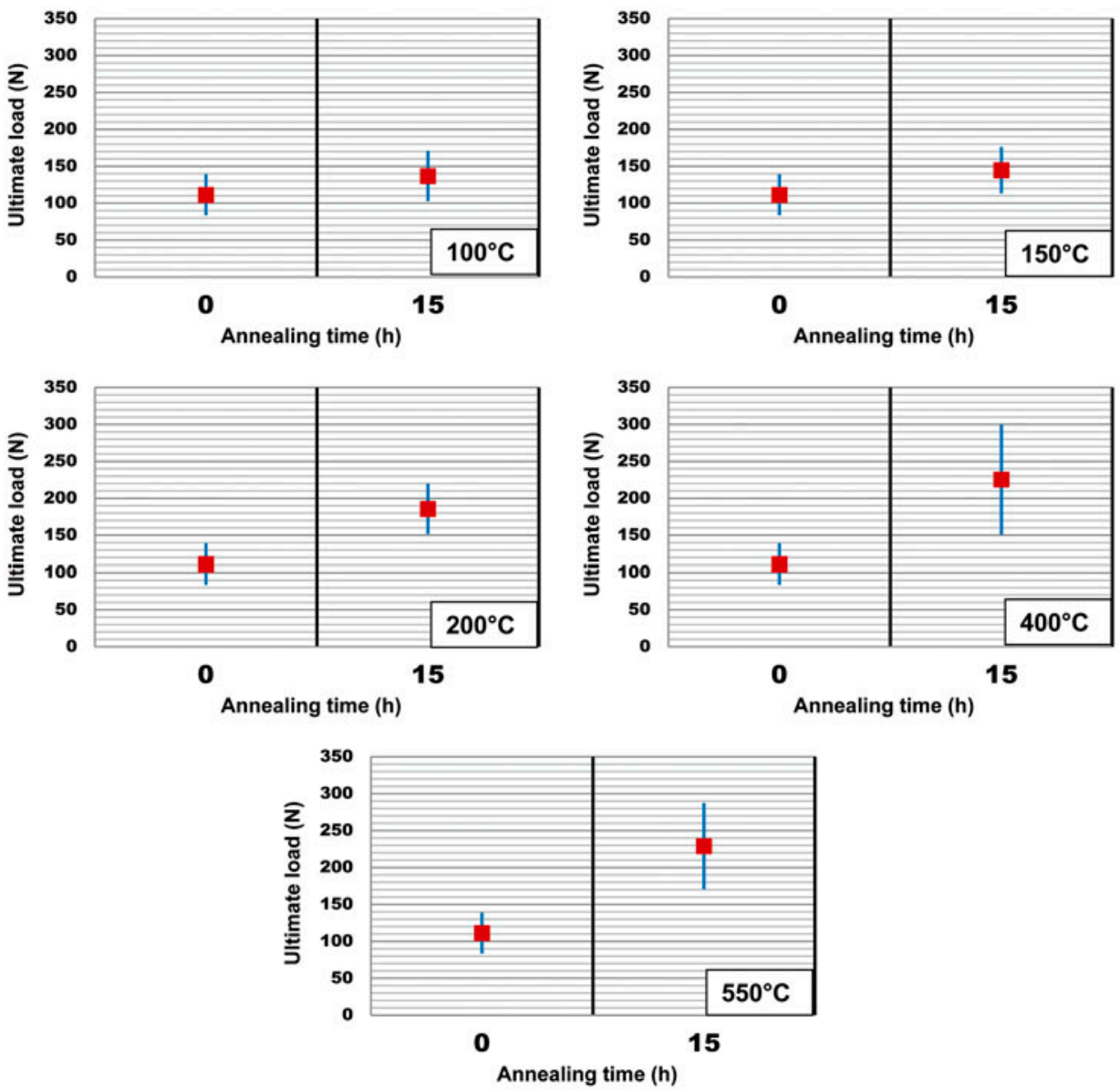

Figure 14. Annealing time influence at different temperatures on Zerodur $^{\mathbb{R}}$ glass tested in double shear configuration: average values and standard deviations of measured ultimate loads.

can be modelled using a kinetic model. $[13,14]$ When temperature increases, there are changes in the nature of bonds at the interface, at the passage between phase I and phase II, hydrogen bonds between clusters of water break to form tetramers of water, and a double hydrogen bond appears between surfaces. Thus, between 200 and $700{ }^{\circ} \mathrm{C}$, the following reaction is triggered:

$$
\mathrm{SiOH}:\left(\mathrm{OH}_{2}\right)_{2}:\left(\mathrm{OH}_{2}\right)_{2}: \mathrm{SiOH} \stackrel{k_{1}}{\rightarrow} \mathrm{SiOH}: \mathrm{SiOH}+\left(\mathrm{H}_{2} \mathrm{O}\right)_{4}
$$

Up to $700^{\circ} \mathrm{C}$ :

$$
\begin{gathered}
\left(\mathrm{H}_{2} \mathrm{O}\right)_{4} \rightarrow\left(\mathrm{H}_{2} \mathrm{O}\right)_{3}+\mathrm{H}_{2} \mathrm{O} \uparrow \rightarrow\left(\mathrm{H}_{2} \mathrm{O}\right)_{2}+\mathrm{H}_{2} \mathrm{O} \uparrow \rightarrow 2 \mathrm{H}_{2} \mathrm{O} \\
\mathrm{SiOH}: \mathrm{SiOH} \rightleftarrows \mathrm{SiOSi}+\mathrm{H}_{2} \mathrm{O} \\
\mathrm{SiOH}: \mathrm{SiOH} \stackrel{k_{2}}{\longrightarrow} \mathrm{SiOSi}+\mathrm{H}_{2} \mathrm{O}
\end{gathered}
$$


where $k_{1}$ and $k_{2}$ are the rate constants of reaction.

By supposing reaction (5), total we have:

$$
\frac{\mathrm{d}[\mathrm{SiOH}: \mathrm{SiOH}]}{\mathrm{dt}}=k_{1}\left[\mathrm{SiOH}:\left(\mathrm{OH}_{2}\right)_{2}:\left(\mathrm{OH}_{2}\right)_{2}: \mathrm{SiOH}\right]=k_{1}\left(n_{0}-[\mathrm{SiOH}: \mathrm{SiOH}]\right.
$$

with:

$$
k_{1}=\frac{1}{\tau} e^{\left(-\frac{E_{a 1}}{K T}\right)}
$$

where $[\mathrm{SiOH}: \mathrm{SiOH}]$ represent the number of double hydrogen bonds between $\mathrm{Si}-\mathrm{OH}$ of the both surfaces, $\frac{\mathrm{d}[\mathrm{SiOH}: \mathrm{SiOH}]}{\mathrm{d} t}$ represent the reaction rate of the double hydrogen formation. $K$ is the Boltzmann constant, $E_{a 1}$ is the activation energy of the reaction, $n_{0}$ the number of adhesion site, $\tau$ the time characteristic constant and $T$ absolute temperature. At room temperature, the activation energy is around $50 \mathrm{meV}$, the energy of a hydrogen bond.[14] The solution to Equation (9) is:

$$
[\mathrm{SiOH}: \mathrm{SiOHi}](t)=n_{0}\left(1-e^{\left(-k_{1} t\right)}\right)
$$

where $t$ is the time. We make the assumption that the gain of surfaces energy is proportional to the number of double hydrogen bonds $\mathrm{Si}-\mathrm{OH}: \mathrm{Si}-\mathrm{OH}$ and we obtain the following expression for the bonding energy $W$ (Figure 15):

$$
W=\left(W_{\mathrm{II}}-W_{\mathrm{I}}\right)\left(1-e^{\left(-k_{1} t\right)}\right)+W_{\mathrm{I}}
$$

with $W_{\mathrm{I}}$ and $W_{\text {II }}$ maximum specific surface energy on phase I and phase II, respectively.

Figure 15 presents the evolution of the kinetic model for different annealing time. Thus, in this kinetic model, the evolution of the bonding energy with annealing parameters is exponential. The evolution of the ultimate force with thermal treatment parameters on Figure 16 also shows the same kind of exponential evolution. Moreover, we have made the assumption that the bonding energy and the ultimate force are proportional, the use of the kinetic model to explain the evolution of the mechanical

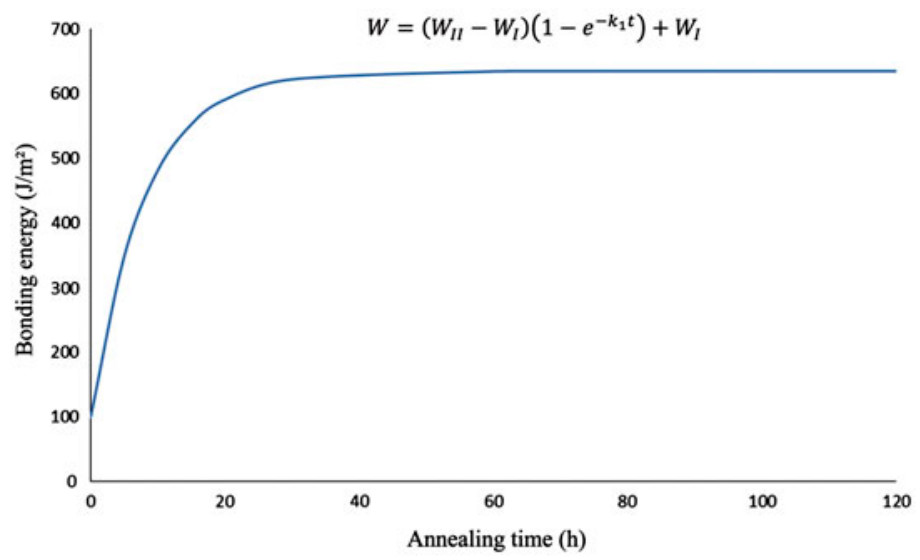

Figure 15. Evolution of the bonding energy modelled using Equation (12) with annealing temperature and time. 


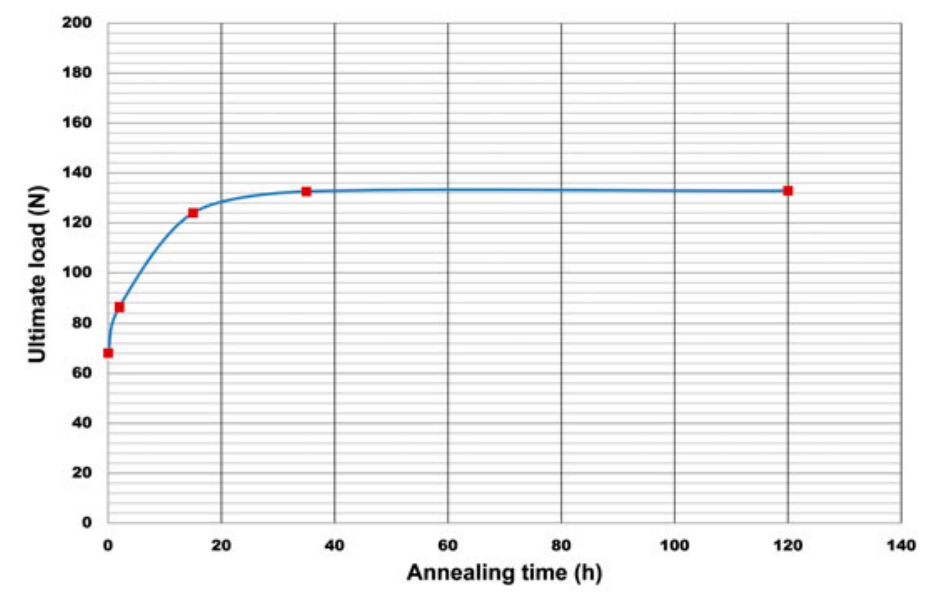

Figure 16. Annealing time influence at $200{ }^{\circ} \mathrm{C}$ on fused silica glass tested in double shear configuration: confrontation with a kinetic model of bonding energy.

resistance with annealing time is validated. Furthermore, results also show a kind of equivalence between long-time annealing at low temperature and short-time annealing at high temperature as shown in Figures 12-14.

\subsection{Influence of roughness}

The results, in Figures 17 and 18, show the influence of roughness combined with thermal treatment $-120 \mathrm{~h}$ at $200{ }^{\circ} \mathrm{C}$ and $120 \mathrm{~h}$ at $130^{\circ} \mathrm{C}$, respectively, for fused silica glass and Zerodur ${ }^{\circledR}$ samples - on the ultimate load measured. The mechanical strength increases until a roughness of $0.6 \mathrm{~nm}$ RMS then decreases. Although those results do not agree with literature in other context $[1,8,9,12]$ and suggest that - for the Winlight Optics Company surface preparation - a higher roughness is better. A first explanation of those results could be the friction of surfaces during double shear tests experiments; moreover, low roughness leads to the appearance of residual stresses on surfaces during polishing process. Furthermore, between 150 and $450{ }^{\circ} \mathrm{C}$, the bonding energy - thus
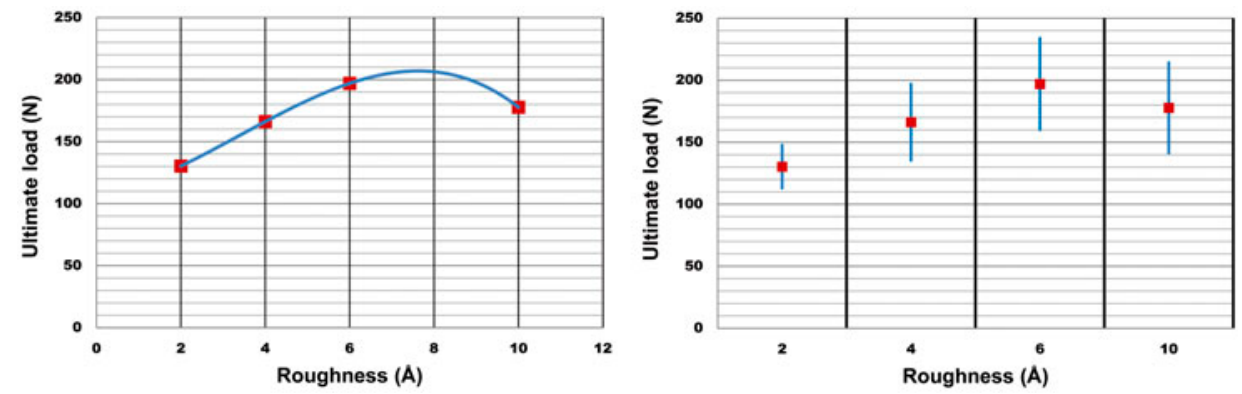

Figure 17. Roughness influence combined with thermal treatment $\left(200^{\circ} \mathrm{C}, 120 \mathrm{~h}\right)$ on fused silica glass tested in double shear configuration: average values and standard deviations of measured ultimate loads. 

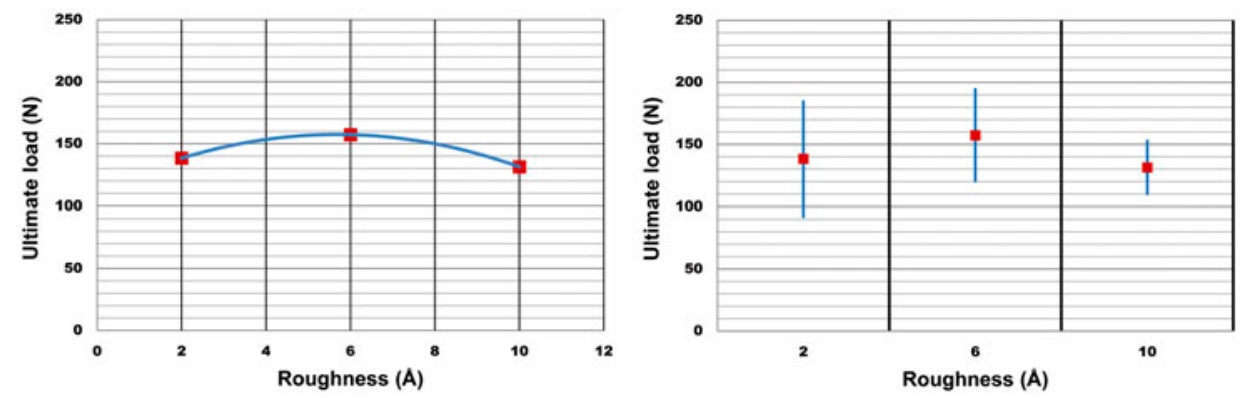

Figure 18. Roughness influence combined with thermal treatment $\left(130^{\circ} \mathrm{C}, 120 \mathrm{~h}\right)$ on Zerodur ${ }^{\circledR}$ glass tested in double shear configuration: average values and standard deviations of measured ultimate loads.

the mechanical strength - is limited by the contacted area (Figure 10) and, in case of high roughness, contacted zones are higher in explaining the results. Adhesion also depends on the height of asperities, the radius of curvature, the wavelength, the real contact area and the local stiffness of contact surfaces.[31-33]

Thus, the existence of a maximum roughness of $0,6 \mathrm{~nm}$ RMS suggests that a medium roughness, compromised between all the previous parameters, is better for the Winlight Optics Company process. Moreover, results of Zerodur ${ }^{\circledR}$ samples are worse than fused silica samples. This could be explained by the temperature of thermal treatment. Indeed, the curve on Figure 4 shows a inflection point at $130{ }^{\circ} \mathrm{C}$, characterizing surely a change in the microstructure leading to a sharp decrease of mechanical properties.

\subsection{Influence of humidity level}

We have also studied the influence of relative air humidity during the room temperature contacting step. Results related in Figures 19 and 20 show that the mechanical strength presents a maximum of $32 \%$ for fused silica glass samples and $55 \%$ for Zerodur ${ }^{\circledR}$ samples. Those results can be explained by the size of water clusters. Indeed, we have shown that there is formation of clusters of water at the interface. Thus, if there is more molecular water at the interface, clusters would be higher. And then, distance between
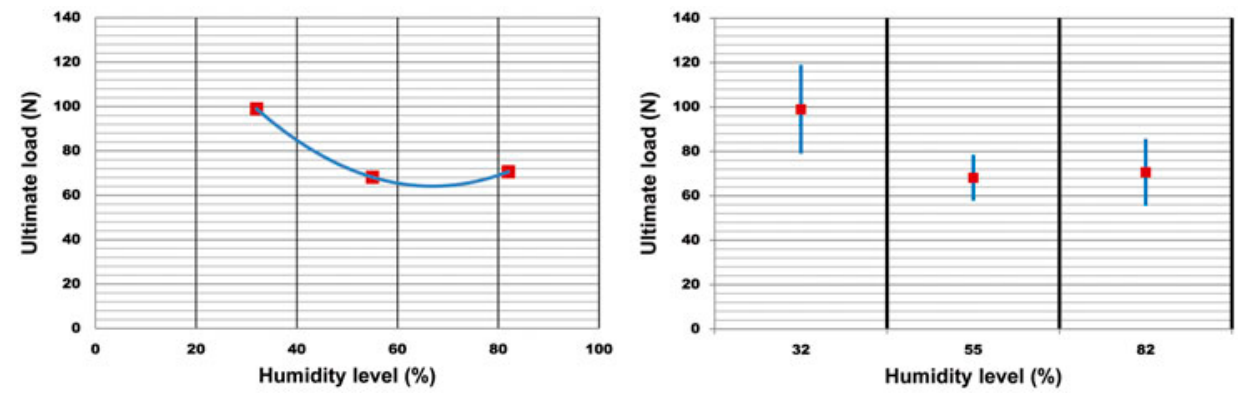

Figure 19. Humidity level influence on fused silica glass tested in double shear configuration: average values and standard deviations of measured ultimate loads. 

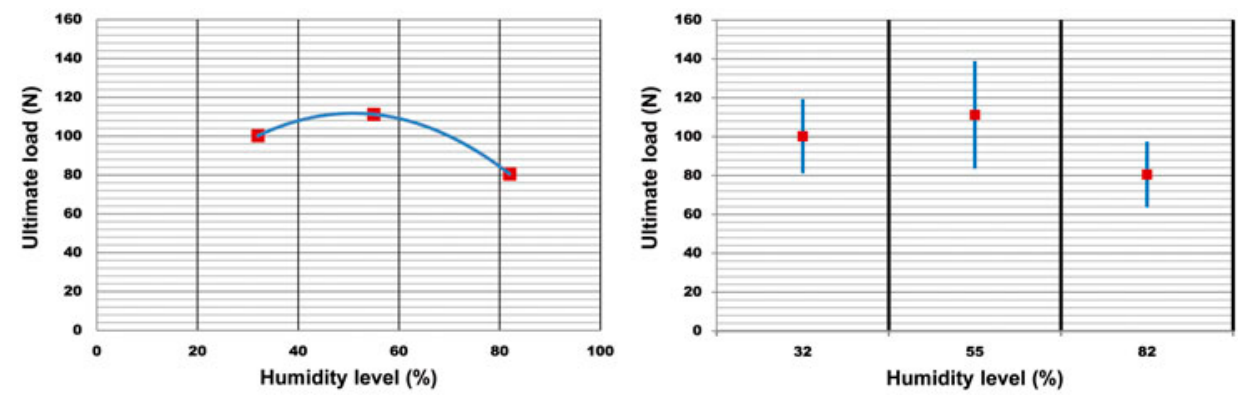

Figure 20. Humidity level influence on Zerodur ${ }^{\circledR}$ glass tested in double shear configuration: average values and standard deviations of measured ultimate loads.

the two surfaces would be higher resulting by a decrease of the bonding energy. Moreover, when there is too much water, we could lead to think that there is a phenomenon of glass damaging.

\subsection{Dispersion of the results}

All the results show lots of dispersion, which can be explained by the brittle behaviour of the direct bonding and heavy sensitivity of the mechanical tests to the presence of defects along the interface. Results strongly depend of the infinitesimal defects present in the bonded interface and depend of their location. However, due to the high number of samples, the tests coupled with a statistical study allow us to identify highly interesting trends in the point of view of the understanding of the interface behaviour.

\subsection{Optimal parameters}

Despite dispersion of the double shear test, results give a good idea of optimal parameters to apply in order to increase the mechanical strength of bonded interfaces. In order to not degrade optical properties of materials, annealing temperature cannot be higher than $200^{\circ} \mathrm{C}$ for both types of samples. As shown in Section 2, there is a kind of equivalence between annealing time and temperature, thus in order to have stronger bonds at $200{ }^{\circ} \mathrm{C}$, thermal treatment has to be long. Based on all the double shear tests results, the chosen parameters are $200^{\circ} \mathrm{C}$ during $120 \mathrm{~h}$ for both fused silica and Zerodur ${ }^{\circledR}$ samples. We also have chosen $200^{\circ} \mathrm{C}$ for Zerodur ${ }^{\circledR}$ samples due to sharp decrease of mechanical properties at $130{ }^{\circ} \mathrm{C}$. Then, roughness chosen is $0.4 \mathrm{~nm}$ RMS for all the samples - compromise between literature and experimental results, $32 \%$ of humidity for Zerodur ${ }^{\circledR}$ samples and $55 \%$ of humidity for fused silica samples.

\section{Validation of optimal parameters}

In the last section, optimal parameters have been found. In this section, to validate this choice, those parameters are compared to the initial conditions - no thermal treatment applied on samples - using cleavage test which is the Winlight Optics Company validation test. Results presented on Figures 21 and 22 show an increase of the mechanical resistance with optimal parameters, thus an improvement with the new parameters. 


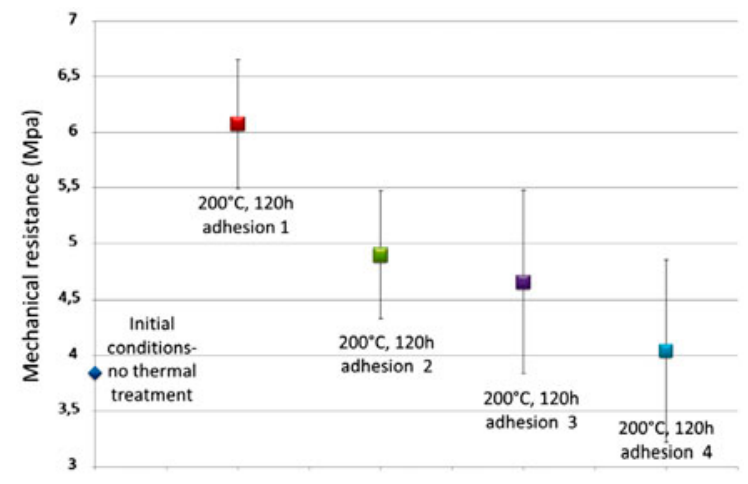

Figure 21. Comparison between initial parameters (no thermal treatment) and optimal parameters $\left(200^{\circ} \mathrm{C}\right.$ during $\left.120 \mathrm{~h}\right)$ in cleavage test configuration: for successive re-adhesions of fused silica samples.

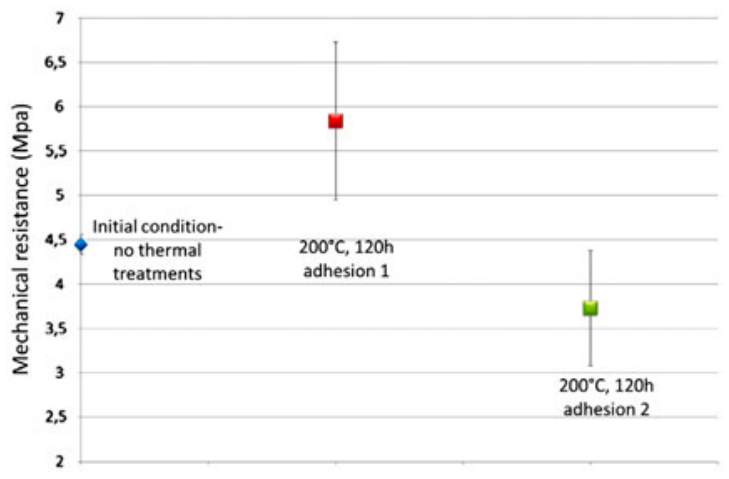

Figure 22. Comparison between initial parameters (no thermal treatment) and optimal parameters $\left(200^{\circ} \mathrm{C}\right.$ during $\left.120 \mathrm{~h}\right)$ in cleavage test configuration: for successive re-adhesions of Zerodur $^{\mathbb{B}}$ samples.

Moreover, mechanical resistance slightly linearly decreased with successive adhesion/ cleavage test/re-adhesion highlighting a damaging phenomenon of the bonded interfaces with successive re-adhesion made in the experiments. This phenomenon was also observed on the wetting tests results. Results for Zerodur ${ }^{\circledR}$ samples are a little worse than results for fused silica sample, because, samples have already undergone other treatment before those experiments. The results confirm the use of optimal parameters found to increase the mechanical resistance of samples.

\section{Conclusion}

The analysis of fused silica glass and Zerodur ${ }^{\circledR}$ surfaces confirm the reversibility (with damaging) of the process when no thermal treatments are applied i.e. when no covalent bonds are responsible for adhesion. Moreover, Zerodur ${ }^{\mathbb{B}}$ samples seem to be a better candidate for direct bonding. This result is confirmed by double shear tests results. Despite the dispersion of the experiments, optimal parameters of the process have been 
found, annealing treatment at $200{ }^{\circ} \mathrm{C}$ during $120 \mathrm{~h}$ for fused silica glass samples with a $0.4 \mathrm{~nm}$ RMS roughness and $55 \%$ of humidity, and $200^{\circ} \mathrm{C}$ during $120 \mathrm{~h}$ with a $0.4 \mathrm{~nm}$ RMS roughness and $32 \%$ of humidity for Zerodur ${ }^{\circledR}$ samples. Moreover, a kind of equivalence between a long thermal treatment at low temperature and a short thermal treatment at high temperature appears. Cleavage tests performed confirm the choice of the optimal parameters and highlight a damaging phenomenon of bonded interfaces with successive re-adhesion. With these optimal parameters, the mechanical strength is twice as much as the strength obtained with the initial parameters. We found a way to increase the mechanical strength of direct bonded interfaces for the Winlight Optics procedure.

The final aim of this work consists in the development of an interface mechanical model of the direct bonding. The implemented law relates the bonding energy, the mechanical critical strain energy, the process parameters and the chemical kinetic in a multi-physic and multi-scale formalism. Soon, a wedge test will be set up to measure the bonding energy vs. process parameters in order to identify the law of the direct bonding model and to implement it in a finite elements model. For the future, new investigations will be lead on to find new original process in order to improve the mechanical strength and to develop simulation of complex spatial optical assemblies.

\section{References}

[1] Tong QY, Gösele U. Semiconductor wafer bonding: recent developments. Mat. Chem. Phys. 1994;37:101-127.

[2] Kendall K. Molecular adhesion and its applications. Birmingham: Kluwer Academic; 2001.

[3] Ventosa C, Rieutord F, Libralesso L, Morales C, Fournel F, Moriceau H. Hydrophilic low-temperature direct wafer bonding. J. Appl. Phys. 2008;104:123524-123530.

[4] Nakanishi H, Nishimoto T, Nakamura R, Yotsumoto A, Yoshida T, Shoji S. Studies on $\mathrm{SiO}_{2}-\mathrm{SiO}_{2}$ bonding with hydrofluoric acid. Room temperature and low stress bonding technique for MEMS. Sens. Actuat., A-Phys. 2000;79:237-244.

[5] Berthold A, Vellekoop MJ. IC-compatible silicon wafer-to-wafer bonding. Sens. Actuat., A-Phys. 1997;60:208-211.

[6] Laurent F, Renault E, Kosmalski J, Adjali L, Boudon D, Bacon R, Caillier P, Remillieux A, Salaun Y, Delabre B. MUSE image slicer: test results on largest slicer ever manufactured. In: Atad-Ettedgui E, Lemke D, editors. Proceedings of SPIE 7018, Advanced Optical and Mechanical Technologies in Telescopes and Instrumentation; Marseille; 2008, 70180J. doi: $10.1117 / 12.789285$

[7] Pamplona T, Rossin Ch, Martin L, Moreaux G, Prieto E, Laurent P, Grassi E, Boit J-L, Castinel L, Garcia J, Milliard B. Three bipods slicer prototype: tests and finite element calculations. In: Atad-Ettedgui E, Lemke D, editors. Proceedings of SPIE 7018, Advanced Optical and Mechanical Technologies in Telescopes and Instrumentation; Marseille; 2008, 701828. doi: $10.1117 / 12.789243$

[8] Plobl A, Krauter G. Wafer direct bonding: tailoring adhesion between brittle materials. Mater. Sci. Eng. 1999;R25:1-88.

[9] Liao G, Shi T, Lin X, Ma Z. Effect of surface characteristic on room-temperature silicon direct bonding. Sens. Actuat., A-Phys. 2010;158:335-341.

[10] Yu HH, Suo Z. A model of wafer bonding by elastic accommodation. J. Mech. Phys. Solids. 1998;46:829-844.

[11] Gösele U, Bluhm Y, Kästner G, Kopperschmidt P, Kräuter G, Scholz R, Schumacher A, Senz St, Tong Q-Y, Huang L-J, Chao Y-L, Lee TH. Fundamental issues on wafer bonding. J. Vac. Sci. Technol., A. 1999;A17:1145-1153.

[12] Gui C, Elwenspoek M, Tas N, Gardeniers JGE. The effect of surface roughness on direct wafer bonding. J. Appl. Phys. 1999;85:7448-7455.

[13] Kissinger G, Kissinger W. Void-free silicon-wafer-bond strengthening in the $200-400{ }^{\circ} \mathrm{C}$ range. Sens. Actuat., A-Phys. 1993;36:149-156. 
[14] Stengl R, Tan T, Gösele U. A model for the silicon wafer bonding process. Jpn. J. Appl. Phys. 1989;28:1735-1741.

[15] Rayssac O, Olivier M, Stoemenos I, Cartier AM, Aspar B. Silicon-on-insulator technology and devices. The Electrochemical Society Proceedings Series; 2001; Pennington, NJ, X PV 03:39.

[16] Tang Z, Shi T, Liao G, Liu S. Modeling the formation of spontaneous wafer direct bonding under low temperature. Microelectron. Eng. 2008;85:1754-1757.

[17] Johnson KL. The adhesion of two elastic bodies with slightly wavy surfaces. Int. J. Solids Struct. 1995;32:423-430.

[18] Galanov BA. Models of adhesive contact between rough elastic solids. Int. J. Mech. Sci. 2011;53:968-977.

[19] Liao G, Lin X, Nie L, Shi T. Surface roughness modeling for silicon direct bonding. IEEE Trans. Compon., Packaging Manuf. Technol. 2011;1:1171-1177.

[20] Lai S-I, Lin H-Y, Hu C-T. Effect of surface treatment on wafer direct bonding process. Mater. Chem. Phys. 2004;83:265-272.

[21] Klier K, Zettlemoyer AC. Water at interfaces: molecular structure and dynamics. J. Colloid Interface Sci. 1977;58:216-229.

[22] Iler RK. The chemistry of silica. New York (NY): Wiley; 2001.

[23] Ventosa C, Rieutord F, Libralesso L, Morales C, Fournel F, Moriceau H. Hydrophilic low-temperature direct wafer bonding. J. Appl. Phys. 2008;104:123524-123526.

[24] Ventosa C, Morales C, Libralesso L, Fournel F, Papon AM, Lafond D, Moriceau H, Penot JD, Rieutord F. Mechanism of thermal silicon oxide direct wafer bonding. Electrochem. Solid States Lett. 2009;12:375-379.

[25] Liao G, Shi T, Lin X, Ma Z. Effect of surface characteristic on room-temperature silicon direct bonding. Sens. Actuat., A-Phys. 2010; 158:335-341.

[26] Lindig O, Pannhorst W. Thermal expansion and length stability of Zerodur in dependence on temperature and time. Appl. Opt. 1985;24:3330-3334.

[27] Cocheteau N, Lebon F, Rosu I, Maurel-Pantel A, Ait Zaid S, Savin De Larclause I. On the modelling of the direct bonding of two silicon surfaces. In: Proceedings of the 11th International Conference on Computational Structures Technology; 2012; Dubrovnik (Croatia).

[28] Gutjahr K, Martini T, Gösele U. Concept of wafer debonding. Electrochem. Soc. Proc. 1998;97:72-74.

[29] Del Bene J, Pople JA. Theory of molecular interactions. I. Molecular orbital studies of water polymers using a minimal slater-type basis. J. Chem. Phys. 1970;52:4858-4866.

[30] Bertholet Y, Iker F, Raskin JP, Pardoen T. Steady-state measurement of wafer bonding cracking resistance. Sens. Actuat., A-Phys. 2004;110:157-163.

[31] Liao G. Effect of surface characteristic on room-temperature silicon direct bonding. Sens. Actuat., A-Phys. 2010;158:335-341.

[32] Hui CY, Lin YY, Baney JM, Kramer EF. The mechanics of contact and adhesion of periodically rough surfaces. J. Polym. Sci., Part B: Polym. Phys. 2001;39:1195-1214.

[33] Tang Z. Modeling the formation of spontaneous wafer direct bonding under low temperature. Microelectron. Eng. 2008;85:1754-1757. 